\title{
ERRATA
}

\section{Seismicity and crustal structure in the vicinity of the southern Itoigawa-Shizuoka Tectonic Line}

\author{
Yannis Panayotopoulos, Naoshi Hirata, Hiroshi Sato, Takaya Iwasaki, Aitaro Kato,
}

Kazutoshi Imanishi, Yasuto Kuwahara, and Ikuo Cho

Earth Planets Space, Vol. 62, pp. 223-235, doi:10.5047/eps.2009.11.007, 2010

In Fig. 11, the horizontal scale of the bottom depth section was not in accordance to the scale of the map view figure. In addition, several epicenters of earthquakes occurring at depths larger than $30 \mathrm{~km}$ were also plotted on the map view figure. Figure 11 should be replaced as given below, while the discussion and conclusions are not subject to correction.

Figure 11 and the caption on p. 232 should read as follows:

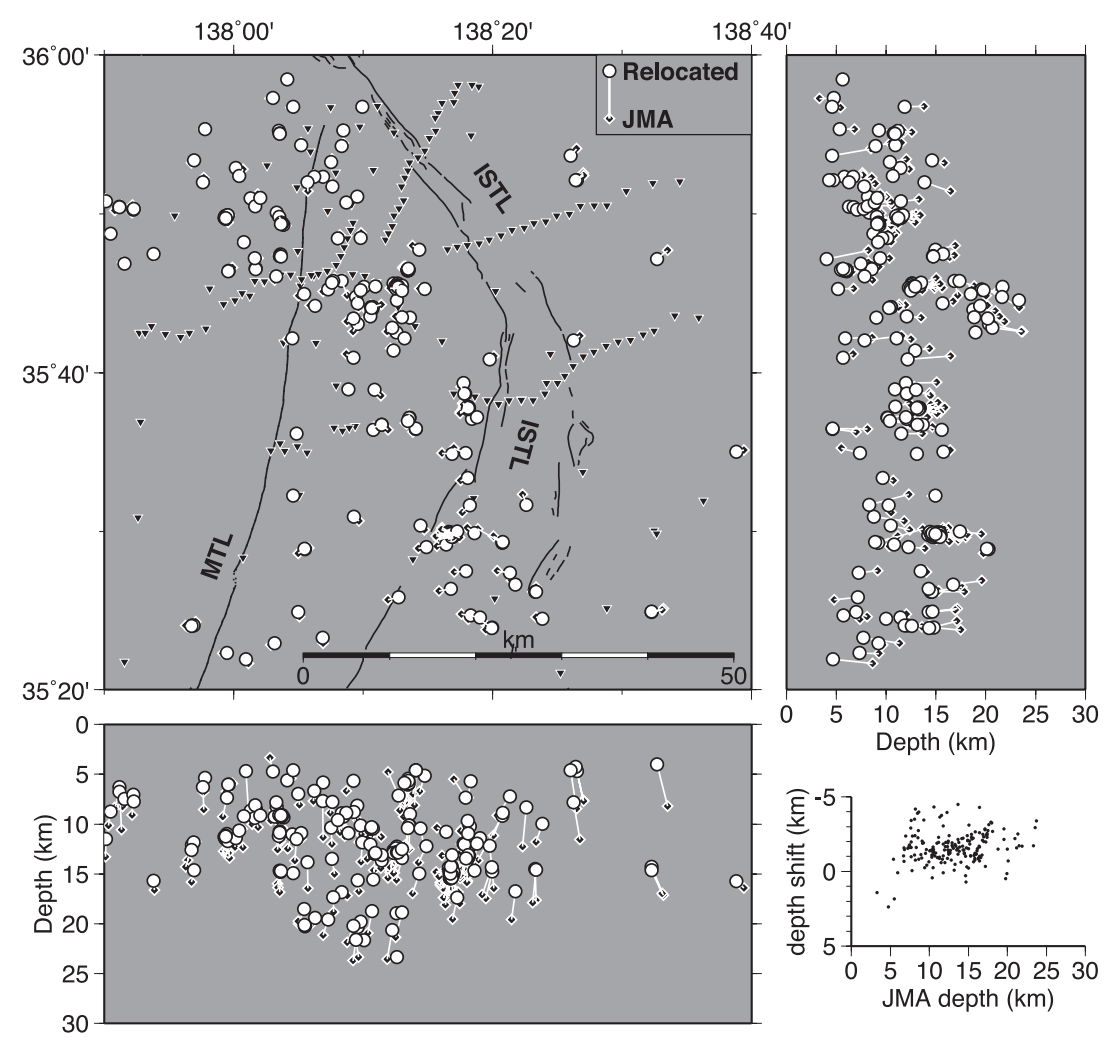

Fig. 1. Hypocenter distribution near the southern segments of the ISTL fault system after the DD tomography relocation. White circles: relocated events. Black diamonds: location determined by the Japanese Meteorological Agency (JMA). White connecting line: shift in the epicentral location and hypocentral depth. Black inverted triangles: stations used in the DD tomography inversion. The events were relocated an average of approximately $2 \mathrm{~km}$ shallower than the JMA position. 